\title{
USING SLIDES TO TEST FOR CHANGES IN CROWN DEFOLIATION ASSESSMENT METHODS PART II: APPLICATION OF THE IMAGE ANALYSIS SYSTEM CROCO
}

\author{
MATTHIAS DOBBERTIN, ${ }^{1, *}$ CHRISTIAN HUG $^{1}$ and NOBUYA MIZOUE ${ }^{2}$ \\ ${ }^{1}$ Swiss Federal Institute for Forest, Snow and Landscape Research, WSL, \\ Zürcherstrasse 111, CH-8903 Birmensdorf, Switzerland; ${ }^{2}$ Faculty of Agriculture, \\ Kyushu University, Fukuoka, Japan, \\ (*author for correspondence,e-mail: matthias.dobbertin@wsl.ch)
}

(Received 24 April 2003; accepted 9 April 2004)

\begin{abstract}
We tested whether the semi-automatic program CROCO can replace visual assessments of slides to detect changes in defoliation assessment methods. We randomly selected a series of slides of 24 Norway spruce trees with 220 field assessments made between 1986 and 1995. The slides had been randomly arranged and assessed by three experts without knowledge of the tree number or the year when the slide was taken. Defoliation scores were computed with CROCO. Each tree had thus three different defoliation scores, field assessments, photo assessments and CROCO scores.

CROCO scores were less correlated with the field assessments (Spearman's rank correlation: 0.67) than were the slide assessments with the field assessments (0.79-0.83). However, CROCO was not biased against the field scores, while slide assessments systematically underestimated defoliation.

In a multi-variate mixed effect model none of the variables tree overlap, tree visibility and light conditions was significant in explaining differences between slide assessors and CROCO scores. The same model applied for the differences from the field scores yielded significant effects for poor light conditions (CROCO and all assessors), for crown overlap (CROCO and one assessor) and for visibility (one assessor). We conclude, therefore, that CROCO can be used to detect past and future changes in assessment methods without bias if poor quality photographs are avoided.
\end{abstract}

Keywords: CROCO, fractals, tree defoliation, assessment methods, quality of photographs

\section{Introduction}

The variable crown, transparency (US, Canada, and some European countries) or crown defoliation (most countries in Europe), used in national health inventories is a subjectively assessed variable (Burkman and Hertel, 1992; Hall, 1995; MüllerEdzards et al., 1997). The assessment methods may intentionally or unintentionally change over time (Köhl, 1991; Innes et al. 1994; Redfern, 1997; Dobbertin and Ghosh, 1998; Landmann et al., 1999; Lorenz et al., 1999; Solberg, 1999; Wulff, 2002). Dobbertin et al. (in press) have shown that time series of slides of trees taken at the time of the field assessment can be successfully used to test if and how methods have changed over time. However, the slide assessment is also prone to observer variability and needs to be repeated every time new slides are taken. Therefore, an objective, reliable and replicable method is required. 
Recently, Mizoue (2002) has developed a semi-automatic image analysis system, called CROCO (which stands for crown condition), to assess the crown transparency from photographs. CROCO calculates a measure of crown transparency (DSO), which is defined as the difference between the fractal dimension of the silhouette of a tree crown (Ds) and the fractal dimension of its outline (Do). The DSO values decreased exponentially with increasing crown defoliation scores when the Swiss (Bosshard, 1986) and British (Innes, 1990) photographic guides were used as references for visual crown defoliation assessments (Mizoue, 2001; Mizoue and Masutani, 2003). It must be noted here that the use of the term 'defoliation' is misleading as the surveys in Switzerland and most other European countries, strictly speaking, do not assess the actual loss of foliage, but rather the transparency of a tree in relation to a fully foliated tree of the same species, branching type and in some surveys the same age growing under similar site conditions. A better term would be 'relative transparency'. As the term 'defoliation' has been used internationally (Lorenz et al., 1999) and in some studies in Switzerland (Ghosh et al., 1995; Dobbertin and Brang, 2001), we will keep this term throughout this paper. Fitting the defoliation scores against the DSO values allows defoliation scores from DSO values to be estimated. Mizoue and Dobbertin (2003) could show that CROCO can serve as a reference to quantify differences in defoliation assessments between countries and the extent to which these change over time.

In this study we used the same time series of Norway spruce slides that had been assessed by three experts to test a change in field assessment methods in Switzerland (Dobbertin et al., in press). We tested first how well the newly developed method CROCO compared with both the slides assessments and the field assessments. We evaluated further how the light conditions in the slides, the crown overlap and the visibility of tree crowns affected the CROCO scores in comparison to the slide assessments and the field assessments.

\section{Data and Methods}

In 1986 and 1987 open-grown trees of the main tree species in Switzerland that were clearly visible were selected and numbered at various locations in Switzerland. Each tree was photographed annually by a professional photographer. The position of the photographer, which was also identical to that of the field observers, remained the same each year. Photographs were taken until 1995, when this service was discontinued due to financial constraints. All the trees were annually assessed for defoliation by field observers using the standard assessment methods. Although the assessing and photographing were done in the summer months July or August: they were not necessarily done at the same time. Thus, weather and light conditions in the slides may not be identical to the actual conditions at the time of the field assessments. 
We restricted our study to Norway spruce, which is the most common tree species in Switzerland (Brassel and Brändli, 1999). In 1986 not all trees had yet been selected. We only used the trees with at least nine slides taken between 1986 and 1995. In 1995 not all the sites could be photographed due to poor weather conditions during that summer. As we could not analyse all the available slides of Norway spruce due to time constraints, we randomly selected 24 trees with time series from four locations comprising 220 assessments of defoliation. All trees had been individually assessed in the field with the exception of a missing field assessment value for one tree in 1990.

The slides were digitized using a film scanner (Quick Scan35, MINOLTA) and defoliation scores were estimated using the CROCO program (Mizoue, 2002). CROCO provides a score of the fractal dimension of a tree crown called DSO (= fractal dimension (D) of the silhouette (S) minus the fractal dimension of the outline $(\mathrm{O})$ ), which is obtained in the following way: First, a rectangular region of interest (ROI), i.e. the largest rectangle around the crown not including overlapping parts was defined. Second, an automatic thresholding algorithm was applied to the blue-filtered gray scale image to generate the crown silhouette image (Mizoue and Inoue, 2001). Then the DSO values were calculated as the fractal dimension of the silhouette minus the fractal dimension of the outline (Mizoue, 2001). The positive bias of DSO values for overlapped trees were removed using the linear regression developed in a previous paper (Mizoue, 2002). Finally, crown defoliation (CD) for a given tree was estimated from the logarithmic equation developed using the Swiss reference photographs following Mizoue and Dobbertin (2003), where CD = $-30.80^{*} \ln (\mathrm{DSO})-20.33$. In theory, CD should be within the range from 0 to $100 \%$. Thus, when $\mathrm{CD}<0$ and $\mathrm{CT}>100$, it is assumed that $\mathrm{CD}$ is 0 and 100, respectively.

The 12 reference photographs used for fitting the curve consist of four photographs each of the three branching types of Norway spruce (comb, brush, and plate type) (Bosshard, 1986). In our study most trees consist of the brush and various intermediate types between brush and comb type. However, Nobuya and Dobbertin (2003) found no differences in DSO scores among the three branching types. In another study, Nobuya and Dobbertin (2004) found that, for some species, the number of reference trees (usually only 4 ) in the photographic guide resulted in significantly different parameter estimates from those produced when using additional data from training courses. However, the parameters of the fitted curve using the 12 Norway spruce reference curves did not change significantly when additional training data were used, so that it was possible to use the original fitted curve.

The slides were randomly arranged and independently assessed by three trained observers (see Dobbertin et al., in press). Neither the year the slide was taken nor the tree number was made known to the observer. Two observers were trainers during 1996-1999, and one observer was the member of a field team, with eight years of experience.

We evaluated whether the differences between the $\mathrm{CROCO}$ and field assessments were due to the quality of the slide or the visibility of the trees in the slide and if these 
differences were similar to those found for the slide assessors. For this purpose, we ranked the slides according to the visibility of the tree crowns (three classes: whole crown visible, only light crown visible, only tip of the tree visible), the light conditions (photo taken with the light, light from the side or overcast, substantial back-light), and how much the neighboring trees overlapped the tree crowns (no overlap, $25 \%$ overlap of crown radius on one or both sides, more than the $25 \%$ overlap; Mizoue, 2002).

\section{Statistical Methods}

We were interested in investigating whether differences existed between CROCO scores and slides assessments and whether such differences depended on photo quality or tree visibility. We also tested whether there was a systematic bias between CROCO and field observations. The correlation between CROCO scores and slide and field assessments was computed using Spearman's partial rank correlation controlling for the nested data structure (series of photos of trees on four plots). We analyzed the differences between the CROCO and the assessor scores for all trees to see if these deviated from 0 using a two-sided Wilcoxon's rank sign test (Bradley, 1968). The effects of slide quality and crown visibility on these differences were tested using a two-sided Wilcoxon's rank sum test (Bradley, 1968). To account for the nested data structure and the randomisation of selected trees, we applied a nested mixed-effect model to the differences (SAS Institute Proc Mixedprcedure; Little et al, 1996; Schabenberger and Pierce, 2002). In the model (1) we treated the variables visibility, light conditions and crown overlap as fixed effects, and the variables plots and trees within plots as random effects:

$$
Y_{i j k l m}=\mu+\alpha_{i}+\beta_{j}+\gamma_{k}+\phi_{l}+\rho_{(l) m}+\varepsilon_{i j k m}
$$

where $\mu$ is the mean effect. $\alpha_{i}$ is the fixed effect for light conditions with $i=1$ for photos taken against the light and 2 for other light conditions. $\beta_{j}$ is the fixed effect for crown overlap with $j=1$ for less than $25 \%$ crown overlap and 2 for at least $25 \%$ crown overlap. $\gamma_{k}$ is the fixed effect for visibility with $k=1$ for crown fully visible and 2 for crown not fully visible. $\phi_{i}$ is the random effect for between plot variance with $l=1-4$ plots $\rho_{(l) m}$ is the random effect for the variance between trees $m$ on plots $l$ with $m=1-24$ trees and $\varepsilon_{i j k m}$ is the residual variance.

\section{Results}

The partial Spearman's rank correlations between CROCO scores and field and slide assessments were highly significant, but lower than the correlations between the slide assessments and the field assessments (Table I). The correlation coefficients 


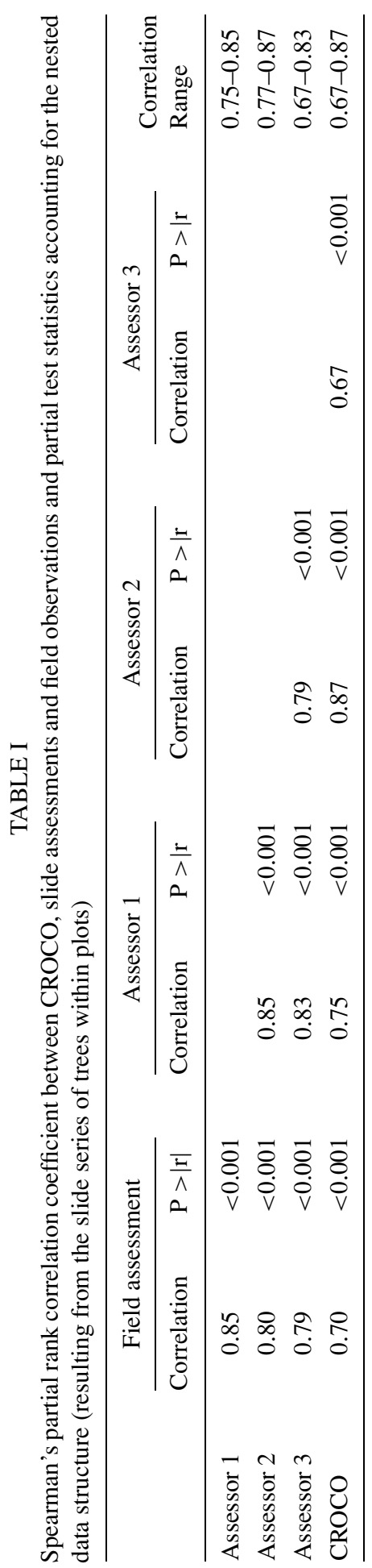


TABLE II

Differences in defoliation scores between CROCO and slide assessments and field observations, their standard deviations and Wilcoxon's sign rank statistics for differences $>0(n=220)$

\begin{tabular}{lccc}
\hline & Mean Difference $(\%)$ & SD $(\%)$ & Wilcoxon's sign rank test $(P \geq|\mathrm{S}|)^{*}$ \\
\cline { 2 - 4 } Assessor 1 & 6.72 & 9.99 & $<0.001$ \\
Assessor 2 & 8.15 & 7.86 & $<0.001$ \\
Assessor 3 & 3.45 & 12.16 & $<0.001$ \\
Field Score & 0.82 & 12.32 & 0.138 \\
\hline
\end{tabular}

${ }^{*}$ Wilcoxon's sign rank test was applied ignoring the nested data structure (slide series of trees within plots), so that $P$-values should only be used for relative comparisons.

between CROCO and the field and the three slide assessors were within the range of correlations between the slide assessors (Table I).

While the slide assessors significantly underestimated the defoliation in comparison with the CROCO scores by between 3.4 and $8.2 \%$, no significant difference was found between the CROCO scores and the field assessments (Table II, see also Figure 1).

Differences between CROCO scores and slide assessments were lower for trees with at least $25 \%$ crown overlap than for trees with less overlap (Table III). Differences between CROCO scores and the slide assessments were also lower for trees

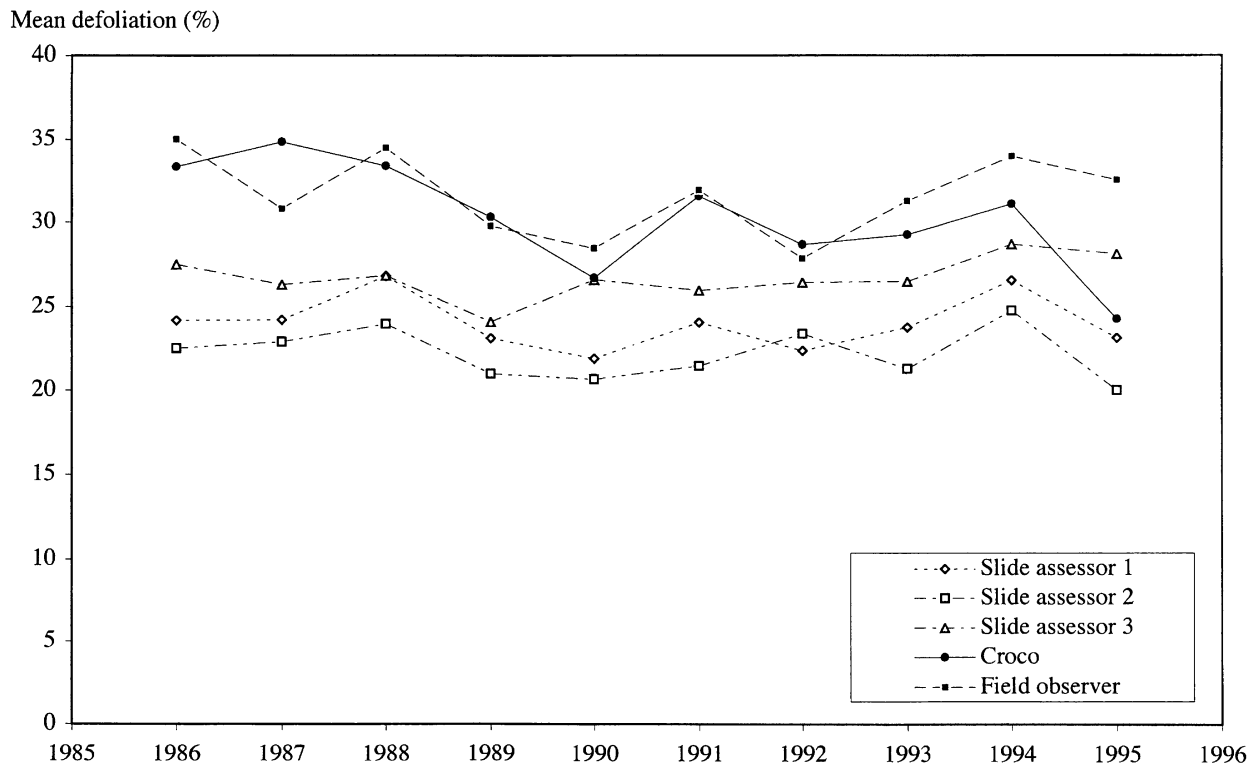

Figure 1. Development of mean defoliation scores of CROCO, three slide assessments and one field assessment between 1986 and 1995 of 24 photographed Norway spruce trees (only 18 trees in 1986, 23 trees in 1990 and 11 trees in 1995 were assessed). 
TABLE III

Differences in defoliation scores between CROCO and slide assessments, standard deviations by crown overlap class and Wilcoxon's rank sum test between trees with at least $25 \%$ overlap and all other trees

\begin{tabular}{|c|c|c|c|c|c|c|c|}
\hline & \multicolumn{2}{|c|}{$\begin{array}{l}\text { Crown overlap } 1 \\
\text { No overlap } \mathrm{N}=182 \\
\end{array}$} & \multicolumn{2}{|c|}{$\begin{array}{l}\text { Crown overlap } 2 \\
25 \% \mathrm{~N}=15 \\
\end{array}$} & \multicolumn{2}{|c|}{$\begin{array}{l}\text { Crown overlap } 3 \\
>25 \% \mathrm{~N}=23 \\
\end{array}$} & \multirow[t]{2}{*}{$\begin{array}{l}\text { Wilcoxon's rank sum } \\
\text { test between Crown } \\
\text { overlap } 1 \text { and } 2+3^{*}\end{array}$} \\
\hline & $\begin{array}{l}\text { Mean } \\
\text { Difference } \\
(\%)\end{array}$ & $\begin{array}{l}\text { SD } \\
(\%)\end{array}$ & $\begin{array}{l}\text { Mean } \\
\text { Difference } \\
(\%)\end{array}$ & $\begin{array}{l}\text { SD } \\
(\%)\end{array}$ & $\begin{array}{l}\text { Mean } \\
\text { Difference } \\
(\%)\end{array}$ & $\begin{array}{l}\text { SD } \\
(\%)\end{array}$ & \\
\hline Assessor 1 & 7.6 & 9.6 & 1.3 & 10.4 & 3.0 & 11.1 & 0.004 \\
\hline Assessor 2 & 8.9 & 7.8 & 4.3 & 6.8 & 4.6 & 7.4 & $<0.001$ \\
\hline Assessor 3 & 4.9 & 12.1 & -0.7 & 11.9 & -5.0 & 8.8 & $<0.001$ \\
\hline
\end{tabular}

*Wilcoxon's sign rank test was applied ignoring the nested data structure (slide series of trees within plots), so that $P$-values should only be used for relative comparisons.

with fully visible crowns than for trees without fully visible crowns (Table IV). For trees photographed against the light the differences between CROCO scores and slide assessments were not different from those for other light conditions (Table V).

When using the mixed effect model to account for the nested data structure and treating trees and plots as random effects, we found that almost $50 \%$ of the variance could be explained by the variation between trees, while between plot variation, not accounted for by the tree variation, was either not existent or comparably small (Table VI). In contrast to the univariate analysis, none of the fixed effects (overlap, visibility and light conditions) were significant in the multi-variate model. On the other hand, if the same model is applied for the differences between field

TABLE IV

Differences in defoliation scores between CROCO and slide assessments, standard deviations by visibility classes and Wilcoxon's rank sum test of not fully visible trees and all other trees

\begin{tabular}{|c|c|c|c|c|c|c|c|}
\hline & \multicolumn{2}{|c|}{$\begin{array}{l}\text { Crown fully } \\
\text { visible } N=64\end{array}$} & \multicolumn{2}{|c|}{$\begin{array}{l}\text { Only light crown } \\
\text { visible } N=51\end{array}$} & \multicolumn{2}{|c|}{$\begin{array}{l}\text { Only tip } \\
\text { visible } N=5\end{array}$} & \multirow[t]{2}{*}{$\begin{array}{l}\text { Wilcoxon's rank sum } \\
\text { test between fully } \\
\text { and not fully visible* }\end{array}$} \\
\hline & $\begin{array}{l}\text { Mean } \\
\text { Difference } \\
(\%)\end{array}$ & $\begin{array}{l}\text { SD } \\
(\%)\end{array}$ & $\begin{array}{l}\text { Mean } \\
\text { Difference } \\
(\%)\end{array}$ & $\begin{array}{l}\text { SD } \\
(\%)\end{array}$ & $\begin{array}{l}\text { Mean } \\
\text { Difference } \\
(\%)\end{array}$ & $\begin{array}{l}\text { SD } \\
(\%)\end{array}$ & \\
\hline Assessor 1 & 8.9 & 8.3 & 5.7 & 10.6 & 6.0 & 4.2 & 0.018 \\
\hline Assessor 2 & 9.1 & 6.2 & 7.9 & 8.5 & 5.0 & 4.5 & 0.007 \\
\hline Assessor 3 & 6.5 & 9.9 & 2.4 & 12.9 & -2.0 & 4.5 & 0.287 \\
\hline
\end{tabular}

*Wilcoxon's sign rank test was applied ignoring the nested data structure (slide series of trees within plots), so that $P$-values should only be used for relative comparisons. 
TABLE V

Differences in defoliation scores between CROCO and slide assessments, standard deviations by light conditions and Wilcoxon's rank sum test of trees photographed against the light and all other trees

\begin{tabular}{|c|c|c|c|c|c|c|c|}
\hline & \multicolumn{2}{|c|}{$\begin{array}{l}\text { With the light } \\
\mathrm{N}=114\end{array}$} & \multicolumn{2}{|c|}{$\begin{array}{l}\text { Light from the side } \\
\text { or overcast } N=84\end{array}$} & \multicolumn{2}{|c|}{$\begin{array}{l}\text { Against the light } \\
\mathrm{N}=22\end{array}$} & \multirow[t]{2}{*}{$\begin{array}{l}\text { Wilcoxon's rank sum } \\
\text { test between 'any-light' } \\
\text { and back-light* }\end{array}$} \\
\hline & $\begin{array}{l}\text { Mean } \\
\text { Difference } \\
(\%)\end{array}$ & $\begin{array}{l}\text { SD } \\
(\%)\end{array}$ & $\begin{array}{l}\text { Mean } \\
\text { Difference } \\
(\%)\end{array}$ & $\begin{array}{l}\text { SD } \\
(\%)\end{array}$ & $\begin{array}{l}\text { Mean } \\
\text { Difference } \\
(\%)\end{array}$ & $\begin{array}{l}\text { SD } \\
(\%)\end{array}$ & \\
\hline Assessor 1 & 9.7 & 7.9 & 6.0 & 6.4 & 8.6 & 10.6 & 0.584 \\
\hline Assessor 2 & 7.3 & 10.4 & 5.1 & 8.2 & 10.2 & 12.7 & 0.107 \\
\hline Assessor 3 & 5.4 & 13.0 & 0.5 & 9.0 & 5.0 & 15.8 & 0.456 \\
\hline
\end{tabular}

*Wilcoxon's sign rank test was applied ignoring the nested data structure (slide series of trees within plots), so that $P$-values should only be used for relative comparisons.

assessments and CROCO scores and between field assessments and slide assessments, we find significant effects for light conditions in all models, for overlap in two models (CROCO and Assessor 3) and for visibility in one model (Assessor 1, see Table VII).

\section{Discussion}

CROCO scores correlated significantly with field and slide assessments, but the correlation was on average slightly lower than for the slide assessments. This differed from the findings from a study of data from the International Intercalibration courses in Slowakia in 1999 (Mizoue and Dobbertin, 2003). During the intercalibration courses observers from various countries assessed the same trees, which were also

\section{TABLE VI}

Mixed effect model of differences between CROCO scores and slide assessments treating plots and trees on plots as random effects, and light conditions, crown overlap and visibility as fixed effects

\begin{tabular}{|c|c|c|c|c|c|c|}
\hline $\begin{array}{l}\text { Parameters } \\
\text { Covariance parameters }\end{array}$ & \multicolumn{2}{|c|}{$\begin{array}{l}\text { Assessor } 1 \\
\text { Variance estimate }\end{array}$} & \multicolumn{2}{|c|}{$\begin{array}{l}\text { Assessor } 2 \\
\text { Variance estimate }\end{array}$} & \multicolumn{2}{|c|}{$\begin{array}{l}\text { Assessor } 3 \\
\text { Variance estimate }\end{array}$} \\
\hline Plots & \multicolumn{2}{|c|}{4.07} & \multicolumn{2}{|c|}{$<0.01$} & \multicolumn{2}{|c|}{$<0.01$} \\
\hline Trees within plots & \multirow{2}{*}{\multicolumn{2}{|c|}{$\begin{array}{l}60.56 \\
67.39\end{array}$}} & \multirow{2}{*}{\multicolumn{2}{|c|}{$\begin{array}{l}43.44 \\
43.60\end{array}$}} & \multirow{2}{*}{\multicolumn{2}{|c|}{$\begin{array}{l}21.55 \\
32.42\end{array}$}} \\
\hline Residuals & & & & & & \\
\hline Fixed effects & $F$ Value & $P>F$ & $F$ Value & $P>F$ & $F$ Value & $P>F$ \\
\hline Light condition & 0.83 & 0.363 & 2.83 & 0.0942 & 0.30 & 0.585 \\
\hline Crown overlap & 0.89 & 0.346 & 1.32 & 0.2523 & 0.23 & 0.635 \\
\hline Visibility & 2.08 & 0.150 & $<0.01$ & 0.9673 & 0.06 & 0.806 \\
\hline
\end{tabular}


TABLE VII

Mixed effect model of differences between field scores and CROCO scores and slide assessments treating plots and trees on plots as random effects and light conditions, crown overlap and visibility as fixed effects (significant fixed effects in bold)

\begin{tabular}{|c|c|c|c|c|c|c|c|c|}
\hline $\begin{array}{l}\text { Parameters } \\
\text { Covariance } \\
\text { parameters }\end{array}$ & \multicolumn{2}{|c|}{$\begin{array}{l}\text { CROCO } \\
\text { Variance estimate }\end{array}$} & \multicolumn{2}{|c|}{$\begin{array}{l}\text { Assessor } 1 \\
\text { Variance estimate }\end{array}$} & \multicolumn{2}{|c|}{$\begin{array}{l}\text { Assessor } 2 \\
\text { Variance estimate }\end{array}$} & \multicolumn{2}{|c|}{$\begin{array}{l}\text { Assessor } 3 \\
\text { Variance estimate }\end{array}$} \\
\hline Plots & \multicolumn{2}{|c|}{13.07} & \multicolumn{2}{|c|}{$<0.01$} & \multicolumn{2}{|c|}{12.63} & \multicolumn{2}{|c|}{6.48} \\
\hline Trees within plots & \multicolumn{2}{|c|}{71.17} & \multicolumn{2}{|c|}{64.37} & \multicolumn{2}{|c|}{30.03} & \multicolumn{2}{|c|}{36.06} \\
\hline Residuals & \multicolumn{2}{|c|}{62.37} & \multicolumn{2}{|c|}{57.11} & \multicolumn{2}{|c|}{41.52} & \multicolumn{2}{|c|}{53.45} \\
\hline Fixed effects & $F$ Value & $P>F$ & $F$ Value & $P>F$ & $F$ Value & $P>F$ & $F$ Value & $P>F$ \\
\hline Light condition & 10.93 & 0.001 & 6.07 & 0.015 & 4.88 & 0.028 & 9.53 & 0.002 \\
\hline Crown overlap & 3.95 & 0.048 & 1.68 & 0.197 & 1.75 & 0.187 & 4.12 & 0.043 \\
\hline Visibility & 0.21 & 0.649 & 3.94 & 0.048 & 0.27 & 0.606 & 0.03 & 0.853 \\
\hline
\end{tabular}

photographed with a digital camera and analyzed with CROCO. For the data on Norway spruce, Scots Pine (Pinus sylvestris L.), European Beech (Fagus sylvatica L.) and pedunculate oak (Quercus robur L.) the correlation coefficients of CROCO with each of the field observers were larger than the median correlation coefficients between the field observers. This indicates that the CROCO scores were highly reliable. The lower correlation of CROCO in our study may be due to the higher experience of the three Swiss slide assessors in assessing photographs.

One advantage of the CROCO score apparent in our study is that it was unbiased in comparison with the field assessments scores, while the slide observers all differed significantly from the field observations. It seems that visually assessing from slides tend to result in lower scores than the actual field scores as discussed in Dobbertin et al. (in press) and Mizoue (1999).

Mizoue (2002) tested how crown overlap is likely to influence the CROCO scores. For that purpose he chose fully visible tree crowns and subsequently removed parts of the crowns starting from the outer edge of the crown. Mizoue found that reducing the crown by $25 \%$ on two sides yielded identical values to using the whole crown. Even reducing the crown by $50 \%$ on one side had little effect on the CROCO score. However, when 50\% and more of the crown were eliminated, CROCO scores were systematically lower. In our study of the Swiss slides we found some effects for CROCO scores already for trees with $25 \%$ overlap on both sides or $50 \%$ on one side of the crown. Although the variable crown overlap was not significant in the multi-variate model for the differences of the CROCO and the slide scores, in the model for the differences between the field and the CROCO scores, the CROCO scores were significantly lower than the field scores for these overlapping crowns.

Other studies have shown, that trees photographed against the light appear more transparent and therefore tend to be assessed with a higher defoliation score than 
when the same trees are seen in the light (Hanisch and Kilz, 1990; Innes 1993). We found the same results for CROCO and visual slide-assessments. While the slide scores and CROCO scores were not different, they both overestimated trees photographed against the light in comparison with the field scores. These results confirm that we should note and emphasize photo quality when testing changes in field assessment methods of crown defoliation (Durrant, in press).

In contrast to the slide assessments, CROCO scores for defoliation were not generally lower than those from the field assessments. When checking changes in field assessment methods in future using photographs, the whole time series of photographs must be reassessed to control for observer variability and bias. On the other hand, with CROCO only the new photographs need to be analyzed. This saves time and money. Therefore, we conclude that CROCO assessments of photographs can be used effectively to detect past and future changes in assessment methods without bias if overlapping tree crowns and photographs taken with back-light are excluded.

\section{Acknowledgements}

The Swiss forest health inventory is a part of the Swiss Forest Investigation Programme, conducted by the Swiss Federal Institute of Forest, Snow and Landscape Research (WSL) in co-operation with the Swiss Federal Forest Administration. The authors would like to thank R. Siegrist for assessing the slides, the various field assessors that have assessed the trees since 1986 and P. Sulser, H. Keusen, and P. Scherer for taking the slides.

\section{References}

Bosshard, W. (ed): 1986, Kronenbilder Eidgenössische Anstalt für das forstliche, Versuchswesen, Birmensdorf, $98 \mathrm{pp}$.

Bradley, J.V.: 1968, Distribution-free Statistical Tests, Prentice-Hall, Inc., Englewood Cliffs, New Jersey, $388 \mathrm{pp}$.

Brassel, P. and Brändli, U.-B. (eds): 1999, Schweizerisches Landesforstinventar. Ergebnisse der Zweitaufnahme 1993-1995, Birmensdorf, Eidgenössische Forschungsanstalt für Wald, Schnee und Landschaft. Bern, Bundesamt für Umwelt, Wald und Landschaft. Stuttgart, Wien, Haupt. Bern, 442 pp.

Burkman, W.G. and Hertel, G.D.: 1992, 'Forest Health Monitoring: A national program to detect, evaluate, and understand change', J. For. 90(9), 27-28.

Dobbertin, M. and Ghosh, S.: 1998, 'Vergleich zwischen zwei Beobachtern bei der Inventur 1997', in P. Brang, (ed): Sanasilva-Bericht 1997. Zustand und Gefährdung des Schweizer Waldes-eine Zwischenbilanz nach 15 Jahren Waldschadenforschung, Berichte, Eidg. Forschungsanstalt für Wald, Schnee und Landschaft, Nr. 345, 84-85. 
Dobbertin, M., Hug, C. and Mizoue, N.: (in press), 'Using slides to test for changes in crown condition assessment methods, Part I: Visual assessment of slides' Environ. Monitor. Assess.

Durrant, D.: (in press), Recommendations for Quality Assurance Methods using Photographs, in Manual on Methods and Criteria for Harmonized Sampling, Assessment, Monitoring and Analysis of the Effects of Air Pollution on Forests, Part II: Visual Assessment of Crown Condition. UN/ECE and EU.

Ghosh, S., Innes, J.L. and Hoffmann, C.: 1995. 'Observer variation as a source of error in assessments of crown condition through time', For. Sci. 41(2), 235-254.

Hall J.P.: 1995, 'Forest health monitoring in Canada: How healthy is the Boreal forest?', Water Air Soil Pollut. 82 (1-2), 77-85.

Hanisch, B. and Kilz, E.: 1990, Waldschäden erkennen: Fichte und Kiefer-Monitoring of Forest Damage Ulmer, Stuttgart, London, Helms, 334 p.

Innes, J.L.: 1990, Assessment of Tree Condition. Forestry Commission Field Book 12, HMSO, London.

Innes, J.L.: 1993, Forest Health: Its Assessment and Status CAB International, Wallingford, UK, 677 pp.

Innes, J.L., Böhm, J.P., Bucher, J.B., Dobbertin, M., Jansen, E., Kull, P., Rigling, A., Walthert, L. and Zimmermann, S.: 1994, Sanasilva-Bericht 1993. Der Zustand des Schweizer Waldes. Berichte der Eidgenössichen Forschungsanstalt für Wald, Schnee und Landschaft 339, $60 \mathrm{pp}$.

Köhl, M.: 1991, Waldschadensinventuren: mögliche Ursachen der Variation der Nadel/ Blattverlustschätzung zwischen Beobachtern und Folgerungen für Kontrollaufnahmen. Allg. For. Jagdtztg. 162(11/12): 210-221.

Landmann, G., Pierrat, J.-C. and Nageleisen, L.-M.: 1999, '1995-1997: Période de réajustement à la hausse de la notation de l'état des cimes des arbres forestiers en France', in Département de la Santé des Forêts (eds), La santé des forêts (France) en 1998, Paris, Ministère de l'Agriculture et de la Pêche (DERF-Département de la Santé des Forêts), pp. 63-66.

Little, R.C., Milliken, G.A., Stroup, W.W. and Wolfinger, R.D. (eds): 1996, SAS ${ }^{\circledR}$ System for Mixed Models. SAS Institute Inc., Cary, North Carolina, USA, 633 pp.

Lorenz M., Müller-Edzards C., Becher G., Fischer R. and Dibbern, B.: 1999, Forest Condition in Europe. Results of the 1998 Crown Condition Survey. 1999 Technical report, Brussels, Geneva, EC-UN/ECE, 84 pp. + ann pp.

Mizoue, N.: 1999, Development of Image Analysis System for Crown Condition Assessment in Forest Health Monitoring, CROCO, Dissertation, Kyushu University, 89 pp.

Mizoue, N.: 2001, 'Fractal analysis of tree crown images in relation to crown transparency', J. For. Plan. 7, 79-87.

Mizoue, N.: 2002, 'CROCO: semi-automatic image analysis system for crown condition assessment in forest health monitoring', J. For. Plan. 8, 17-24.

Mizoue, N., and Inoue, A.: 2001, 'Automatic thresholding of tree crown images', J. For. Plan. 6, $75-80$.

Mizoue, N. and Masutani, T.: 2003, 'Image analysis measure of crown condition, foliage biomass and stem growth relationships of Chamaecyparis obtusa', For. Ecol. Manage. 172, 79-88.

Mizoue, N. and Dobbertin, M.: 2003, 'Detecting differences in crown transparency assessments between countries using the image analysis system CROCO. Environ. Monitor. Assess. 89, 179195.

Mizoue, N. and Dobbertin, M.: (in press), Within country accuracy of tree crown transparency estimates using the image analysis system CROCO: A case study from Switzerland. Environ. Model. Software.

Müller-Edzards, C., de Vries, W. and Erisman, J.W. (eds): 1997, Ten Years of Monitoring Forest Condition in Europe. Studies on Temporal Development, Spatial Distribution and Impacts of 
Natural and Anthropogenic Stress Factors. Technical Background Report, Geneva and Brussels, United Nations Economic Commission for Europe/European Commission, 385 pp.

Redfern, D.B.: 1997, 'National Report, United Kingdom, in C., Müller-Edzards, J.W. Erisman, and W. de Vries, (eds) Ten Years of Monitoring Forest Condition in Europe. Studies on Temporal Development, Spatial Distribution and Impacts of Natural and Anthropogenic Stress Factors. Technical Background Report, Geneva and Brussels, United Nations Economic Commission for Europe/European Commission, pp. 174-177.

Schabenberger, O. and Pierce, F.J.: 2002, Contemporary Statistical Methods for the Plant and Soil Sciences. CRC Press. 738 p.

Solberg, S.: 1999, Forest Health Monitoring: Evaluation of Methods, Trends and Causes Based on a Norwegian Nationwide Set of Monitoring Plots. Dr. agric Thesis, Agricultural University of Norway, ISBN 82-7169-897-4.

Wulff, S.: 2002, 'The accuracy of forest damage assessments-Experiences from Sweden', Environ. Monitor. Assess. 74, 295-309. 